\title{
TIPS Is Not Associated with a Higher Risk of Developing HCC in Cirrhotic Patients: A Systematic Review and Meta-analysis
}

\author{
Bin Chen ${ }^{1}$, Long Pang ${ }^{2}$, Hao-Bin Chen ${ }^{2}$, Dong-Bo Wu ${ }^{1}$, Yong-Hong Wang ${ }^{1}$ and \\ En-Qiang Chen*1 \\ ${ }^{1}$ Center of Infectious Diseases, West China Hospital, Sichuan University, Chengdu, China; ${ }^{2}$ West China School of Medicine, \\ Sichuan University, Chengdu, China
}

\begin{abstract}
Background and Aims: The association between portalsystemic shunt and hepatocellular carcinoma (HCC) development in patients who have cirrhosis is still controversial. This systematic review with meta-analysis was performed to systematically clarify the potential role of portal-systemic shunt in the development of HCC. Methods: The PubMed, Embase, and Cochrane Library databases were searched for potentially eligible literature. Meta-analysis with random-effects model was performed to combine the incidence rates of HCC after portal-systemic shunt. Finally, seven studies were included. In the present review, we mainly focused on 859 patients (365 in the transjugular intrahepatic portal-systemic shunt (TIPS) group and 494 in the non-TIPS group) from five studies to analyze incidence rates after TIPS. Results: At the end of follow-up, there were $66(18 \%, 66 / 365)$ patients who developed HCC after TIPS intervention and 63 (13\%, 63/494) patients who developed HCC after non-TIPS treatments. Pooled estimates with random-effects model did not demonstrate a significant increase of incidence of HCC after TIPS (risk ratio: 1.37 [confidence interval (CI): 0.96 to 1.97 ]; $p=0.08$ ) compared with non-TIPS treatments. Subgroup analyses for those patients with transplanted liver also did not detect a significant difference between the TIPS group and non-TIPS group (risk ratio: 1.10 [CI: 0.59 to 2.07]; $p=0.75$ ). Conclusions: Current evidence suggests that portal-systemic shunt is not associated with a higher risk of HCC development in cirrhotic patients.

Citation of this article: Chen B, Pang L, Chen HB, Wu DB, Wang $\mathrm{YH}$, Chen EQ. TIPS is not associated with a higher risk of developing HCC in cirrhotic patients: A systematic review and meta-analysis. J Clin Transl Hepatol 2019;7(3):232-237. doi: 10.14218/JCTH.2019.00007.
\end{abstract}

\section{Introduction}

Portal-systemic shunt, especially the transjugular intrahepatic portal-systemic shunt (TIPS) introduced in $1989,{ }^{1}$ has become one of the most acceptable treatments of portal

Keywords: Transjugular intrahepatic portal-systemic shunt (TIPS); Hepatocellular carcinoma (HCC); Hepatic cirrhosis; Systematic review.

Abbreviations: CI, confidence interval; HCC, hepatocellular carcinoma; TIPS transjugular intrahepatic portosystemic shunt.

Received: 27 January 2019; Revised: 2 April 2019; Accepted: 5 May 2019

* Correspondence to: En-Qiang Chen, Center of Infectious Diseases, West China Hospital, Sichuan University, No. 37 Guo Xue Xiang, Wuhou District, Chengdu 610041, China. E-mail: chenenqiang1983@hotmail.com hypertension-associated complications because the procedure effectively reduces portal pressure. ${ }^{2-5}$ With the development of medical technology, surgical portal-systemic shunt has been replaced by TIPS, and bare-stent TIPS has been replaced by covered-stent TIPS with extended polytetrafluoroethylene. ${ }^{6}$ Early application of TIPS in cirrhotic patients with variceal bleeding has been recommended to reduce the overall mortality. ${ }^{7}$ Moreover, TIPS has played an increasingly essential role in the management of decompensated liver cirrhosis.

Hepatocellular carcinoma (HCC) remains one of the leading causes of mortality among cirrhotic patients. Early accurate diagnosis is beneficial for improving prognosis of this tumor, and a regular detection program for $\mathrm{HCC}$ has been suggested to high-risk patients. ${ }^{8,9}$ Portal-systemic shunt could generate circulatory, hemodynamic, and functional changes, which might increase the incidence of HCC as suggested in some published studies. ${ }^{10}$ In 1985 , Bjorneboe et al. ${ }^{11}$ reported a higher incidence of developing HCC in shunted patients who survived more than 6 months after operation (relative risk: 3.28; 95\% confidence interval [CI]: 1.52-7.45) compared with non-shunted patients. In 2005, Banares et al. ${ }^{12}$ reported an observational study which suggested cirrhotic patients with application of TIPS may suffer a higher incidence of HCC. As such, a formal HCC monitoring program is highly recommended for these patients, especially for those are not able to receive a short-period or medium-period liver transplantation.

However, incompatible results have been reported regarding the incidence of developing HCC in patients with portalsystemic shunt. In 2005, Libbrecht et al. ${ }^{13}$ published another study which showed that neither the progress of HCC nor the existence and amount of dysplastic nodules was in association with the application of TIPS. In 2013, De Santis and his colleagues ${ }^{14}$ reported a retrospective case-control study with 101 cirrhotic patients in different groups. The median length of follow-up was 56.7 months (range: 8.2-174.5) and 67.8 months (range: $8.3-183.1$ ) for TIPS patients and controls respectively $(p=0.08)$. The cumulative incidence of HCC at $1,3,5$ and 10 years was $2 \%, 7 \%, 18 \%$ and $46 \%$ in the TIPS group and $3 \%, 10 \%, 19 \%$ and $39 \%$ in the control group ( $p=$ 0.19). These results suggested that TIPS did not account for the increased risk of HCC, and unmodified ultrasound supervising was recommended for these patients. Recently, in 2015, Borentain et al. ${ }^{17}$ reported another retrospective study which suggested that TIPS may increase the incidence of liver dysplasia; however, the risk of developing HCC in a transplanted liver was not related to TIPS.

The present systematic review with meta-analysis aims to provide a comprehensive understanding of whether the 
incidence rates of HCC development are statistically different in cirrhotic patients who received TIPS than in those who received non-TIPS treatments, based upon a thorough search of the electronic databases, including PubMed, Cochrane Library, and Embase.

\section{Methods}

\section{Literature search}

A systematic literature search of three databases was independently conducted, including PubMed, Cochrane Library, and Embase. This meta-analysis followed the standard reporting guidelines. ${ }^{15}$ The search was done from the inception of the databases to 20 March 2018. The following keywords were used: TIPS; portal-systemic shunt; surgical shunt; and transjugular intrahepatic portal-systemic shunt. All potential eligible studies were manually searched to find possible relevant publications. No language or publication type or date restriction was set.

\section{Inclusion and exclusion criteria}

Inclusion criteria were as follows: 1) the publications described randomized controlled trials or observational studies; 2 ) the participants in the experimental groups were treated with portal-systemic shunt, while the participants in the control groups were treated with other treatments instead of portal-systemic shunts; 3 ) reporting on the outcome of incidence rate of HCC after treatment. If the data of any paper overlapped or were duplicated among two or more studies by the same study team, only the study with the more complete data or one earlier study were included.

\section{Study selection and data extraction}

The titles and abstracts of identified articles were perused by two of the authors (B.C. and L.P.) working independently after the removal of duplications. Then, full articles were retrieved if further assessment was needed. Data collection was independently carried out by two reviewers. Two authors made their own assessment of the risk of bias of enrolled studies according to the Risk of Bias Tool conferred by the Cochrane Handbook. Divergence was resolved by third opinion.

The extracted and summarized data include first author, publication year, country, study design, publication type, sample size, type of portal-systemic shunt (surgical shunt or TIPS), duration of follow-up, demographic data (age and sex), and the incidence rate of HCC after treatment.

\section{Quality assessment}

The quality of observational studies was evaluated with the Newcastle-Ottawa Scale. The Newcastle-Ottawa Scale measures quality in the three domains of selection, comparability, and exposure. High-quality studies were considered to have a score of 7 or greater, consistent with other metaanalyses. The Cochrane Risk of Bias Tool for assessing risk of bias was used to assess the quality of randomized controlled trials. Study quality was assessed independently by two investigators (C.B. and L.P.) and any discrepancies were addressed by a joint evaluation of the original article.

\section{Statistical analysis}

The primary outcome was the incidence rate of HCC at the end of follow-up of each included study. Discontinuous outcomes were evaluated by odds ratio and a corresponding $95 \%$ confidence interval (CI). The curative effect in continuous variables was expressed as weighted mean difference with corresponding variances. The results were identified as statistically significant when the $p$ value was less than 0.05 . The heterogeneity among the studies was assessed by the $I^{2}$ statistic ( $I^{2}>50 \%$ suggested substantial heterogeneity) and the chi-square test $(p<0.10$ indicated significant statistical heterogeneity). ${ }^{16}$ Publication bias was investigated by the Egger's test. RevMan v5.3 (The Cochrane Collaboration, Software Update, Oxford, UK) was the tool used to extract, pool and analyze the data.

\section{Results}

\section{Literature search and study characteristics}

Of 253 records, 9 met selection criteria ${ }^{11-14,17-20}$ (Fig. 1). Two records were excluded due to no relevant data being available. ${ }^{20}$ Finally, seven studies were included in this review. One was a randomized trial, ${ }^{19}$ and six were observational studies. ${ }^{11-14,17,18}$ Two studies evaluated the incidence rate of HCC after surgical portal-systemic shunts, ${ }^{11,18}$ and five studies evaluated the incidence rate of HCC after TIPS. ${ }^{12-14,17,19}$ We can only make a descriptive review regarding the incidence rate after surgical portal-systemic shunts due to lack of available full-texts. In 1985, Bjorneboe et al. ${ }^{11}$ reported a high risk of HCC in shunted patients alive more than 6 months postoperatively (relative risk: $3.28 ; 95 \% \mathrm{CI}: 1.52-7.45)$ compared with nonshunted patients. However, another study reported that after a mean follow-up of 50 months, no differences were observed between the two groups in relation to the prevalence of HCC after portal-systemic shunt. ${ }^{18}$

In this review, we mainly focused on the analysis of incidence rate after TIPS due to the available data. The fulltexts of the selected five studies were obtained, ${ }^{12-14,17,19}$ and the main characteristics are displayed in Table 1 . Two studies were performed in Spain and another three were conducted in Belgium, Italy, and France respectively. The five total studies involved 859 patients ( 365 in the TIPS group and 494 in the non-TIPS group). The mean age in each study was over 50 years old, and more than $60 \%$ of participants were male. The main cause of cirrhosis was alcohol abuse. Of note, two studies assessed the incidence rate of HCC after TIPS in transplanted livers. ${ }^{13,17}$ According to the methodological assessment, only one randomized controlled trial was considered high quality. ${ }^{19}$ Most observational studies were rated as good quality. ${ }^{12,14,17}$ However, one study with abstract available only was considered to be of unclear quality. ${ }^{13}$ The funnel plots demonstrated no publication bias, as shown in Fig. 2.

\section{Meta-analyses of incidence rates of HCC}

The total five studies involving 859 patients were included for the meta-analysis of incidence rates of HCC after TIPS or other treatments (365 in the TIPS group and 494 in the nonTIPS group). All of these five studies reported the number of patients with de novo HCC in the TIPS group or non-TIPS group. The mean or median follow-up time was reported in three of the studies, ranging from 14.4 to 67.8 months. At the 
Chen B. et al: TIPS is not related to HCC

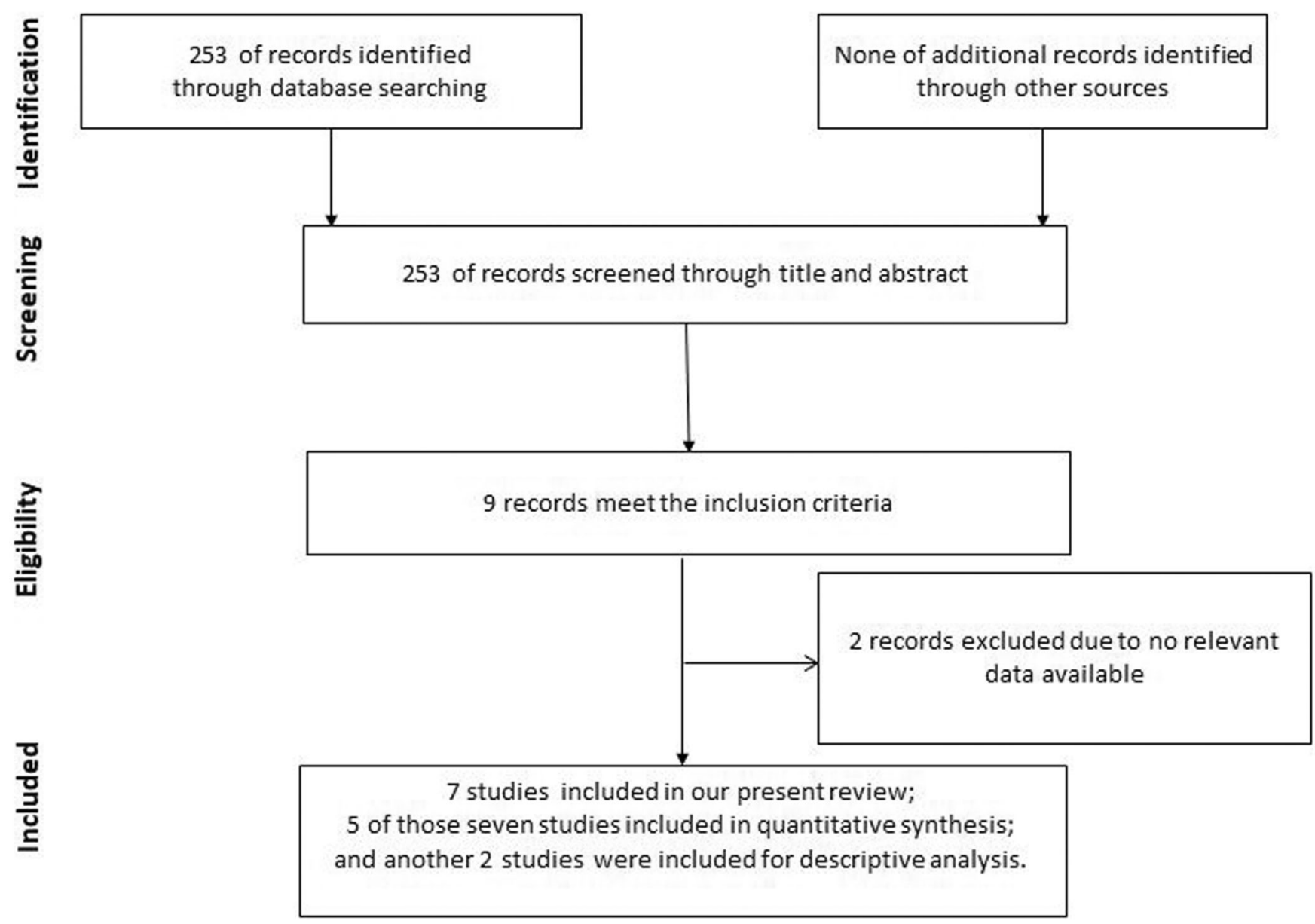

Fig. 1. Flow chart of study selection.

last follow-up, there were $66(18 \%, 66 / 365)$ patients with de novo HCC in the TIPS group and $63(13 \%, 63 / 494)$ patients with de novo HCC in the non-TIPS group. Although the incidence rate of HCC was higher in the TIPS group than in the non-TIPS group, the pooled results did not demonstrate a significant difference between the two groups (relative risk: 1.37 [95\% CI: $0.96-1.97$ ] $p=0.08$, random-effects model) (Fig. 3). No significant heterogeneity between studies was detected $\left(p=0.36 ; I^{2}=8 \%\right)$.

\section{Subgroup analyses of incidence rates of HCC}

Subgroup analysis was performed according to the percentage of cirrhosis patients due to alcohol. Pooled estimates from studies that enrolled more than $50 \%$ of cirrhosis due to alcohol suggested that TIPS was associated with a significant increase of development of HCC (relative risk: 2.02 [95\% CI: 1.053.9]; $p=0.04$, random-effects model) (Fig. 3). However, pooled estimates from studies which enrolled less than $50 \%$ of cirrhosis due to alcohol patients did not demonstrate a significant difference between the two groups (relative risk: 1.11 [95\% CI: 0.73-1.69]; $p=0.63$, random-effects model). We further performed a subgroup analysis assessing the incidence rate of HCC in those patients with transplanted liver, and there was also no significant difference between the TIPS group and the non-TIPS group (relative risk: 1.10 [95\% CI: 0.59-2.07]; $p=0.75$, random-effects model) (Fig. 4).

\section{Discussion}

There is still controversy regarding the influence of portalsystemic shunt on the incidence rate of HCC after shunt procedures. Our present study systematically collected those published studies which evaluated the influence of portalsystemic shunt on development of HCC. This is the first systematic review and meta-analysis focusing on this topic. Due to no relevant data available, meta-analysis was not performed for those studies which assessed whether surgical portal-systemic shunt increased the risk of HCC in cirrhosis. So, this study mainly reported the pooled results with regard to the influence of TIPS on the development of HCC.

In total, five studies were included for meta-analysis. We combined the results with random-effects model, and the pooled estimates did not detect a significant difference regarding the incidence rate of HCC between the TIPS group and the non-TIPS group. Of note, subgroup analysis suggested that TIPS was positively associated with incident HCC in those studies which enrolled more than $50 \%$ of cirrhosis patients due to alcohol. However, there is no other evidence to implicate TIPS as a risk factor for HCC development in 
Chen B. et al: TIPS is not related to HCC

Table 1. Main characteristics of included studies (TIPS vs. non-TIPS group)

\begin{tabular}{|c|c|c|c|c|c|c|c|c|c|}
\hline Study & Year & Country & $\begin{array}{l}\text { Publication } \\
\text { type }\end{array}$ & Study design & $\begin{array}{l}\text { Sample } \\
\text { size, } n\end{array}$ & Age $(y)$ & Male & $\begin{array}{l}\text { Etiology of } \\
\text { alcohol/ } \\
\text { other, } n\end{array}$ & $\begin{array}{l}\text { Follow-up } \\
\text { time }\end{array}$ \\
\hline $\begin{array}{l}\text { Escorsell } \\
\text { et al. }{ }^{19}\end{array}$ & 2002 & Spain & Full-text & $\begin{array}{l}\text { Randomized } \\
\text { controlled trial }\end{array}$ & $47 / 44$ & $\begin{array}{l}57 \pm 9 / \\
56 \pm 11\end{array}$ & $\begin{array}{l}70 \% / \\
80 \%\end{array}$ & $\begin{array}{l}24: 23 / \\
25: 19\end{array}$ & $\begin{array}{l}15.4 / 14.4 \\
\text { months }\end{array}$ \\
\hline $\begin{array}{l}\text { Banares } \\
\text { et al. }{ }^{12}\end{array}$ & 2005 & Spain & Full-text & $\begin{array}{l}\text { Observational } \\
\text { study }\end{array}$ & $\begin{array}{l}138 / \\
138\end{array}$ & $\begin{array}{l}56 \pm 11 / \\
56 \pm 11\end{array}$ & $\begin{array}{l}73 \% / \\
73 \%\end{array}$ & $\begin{array}{l}70: 68 / \\
70: 68\end{array}$ & $\begin{array}{l}30.3 / 31.4 \\
\text { months }\end{array}$ \\
\hline $\begin{array}{l}\text { Libbrecht } \\
\text { et al. }{ }^{13}\end{array}$ & 2005 & Belgium & Letter & $\begin{array}{l}\text { Observational } \\
\text { study }\end{array}$ & $11 / 65$ & $\begin{array}{l}54 \pm 8 / \\
55 \pm 10\end{array}$ & $\begin{array}{l}64 \% / \\
63 \%\end{array}$ & $8: 3 / 22: 43$ & $\begin{array}{l}\text { Not } \\
\text { reported }\end{array}$ \\
\hline $\begin{array}{l}\text { De Santis } \\
\text { et al. }{ }^{14}\end{array}$ & 2014 & Italy & Full-text & $\begin{array}{l}\text { Observational } \\
\text { study }\end{array}$ & $\begin{array}{l}101 / \\
101\end{array}$ & $\begin{array}{l}59 \pm 9 / \\
59 \pm 10\end{array}$ & $\begin{array}{l}64 \% / \\
64 \%\end{array}$ & $\begin{array}{l}27: 74 / \\
27: 74\end{array}$ & $\begin{array}{l}67.8 / 56.7 \\
\text { months }\end{array}$ \\
\hline $\begin{array}{l}\text { Borentain } \\
\text { et al. }{ }^{17}\end{array}$ & 2015 & France & Full-text & $\begin{array}{l}\text { Observational } \\
\text { study }\end{array}$ & $68 / 146$ & $\begin{array}{l}51 \pm 7 / \\
50 \pm 8\end{array}$ & $\begin{array}{l}77 \% / \\
78 \%\end{array}$ & $\begin{array}{l}43: 25 / \\
59: 87\end{array}$ & $\begin{array}{l}\text { Not } \\
\text { reported }\end{array}$ \\
\hline
\end{tabular}

patients with alcoholic cirrhosis. Additionally, subgroup analysis also did not demonstrate that TIPS increased the risk of HCC in transplanted liver. In order to improve the accuracy and reliability of pooled estimates, we did not show the pooled estimates with fixed-effects model in the section of results. However, the pooled results suggested that TIPS was associated with a higher incidence rate of $\mathrm{HCC}$, compared with other treatments (relative risk: 1.41 [95\% CI: 1.01-1.96]; $p=0.04$, fixed-effects model).

Of those five included studies, only one retrospective cohort study suggested that the creation of TIPS may be associated with a higher risk of developing HCC in patients with cirrhosis. ${ }^{12}$ Their results suggested that patients with TIPS had a higher risk of developing HCC than matched controls. Over a 5-year period, the actuarial risk of developing HCC was 34\% in the TIPS group and $25 \%$ in the non-TIPS group. Of note, the rate of liver transplantation was much higher in the non-TIPS group than in the TIPS group in this study, which meant that the number of patients at risk of HCC over time was lower in this group. Furthermore, as mentioned in the section of discussion by authors, selection bias cannot be completely excluded due to the retrospective nature of this study, although researchers of this study performed a careful selection of the non-TIPS cohort to match the TIPS cohort as well as possible.

Some researchers have suggested that the marked decrease of portal blood flow due to TIPS placement might lead to malignant transformation of the cirrhotic liver,

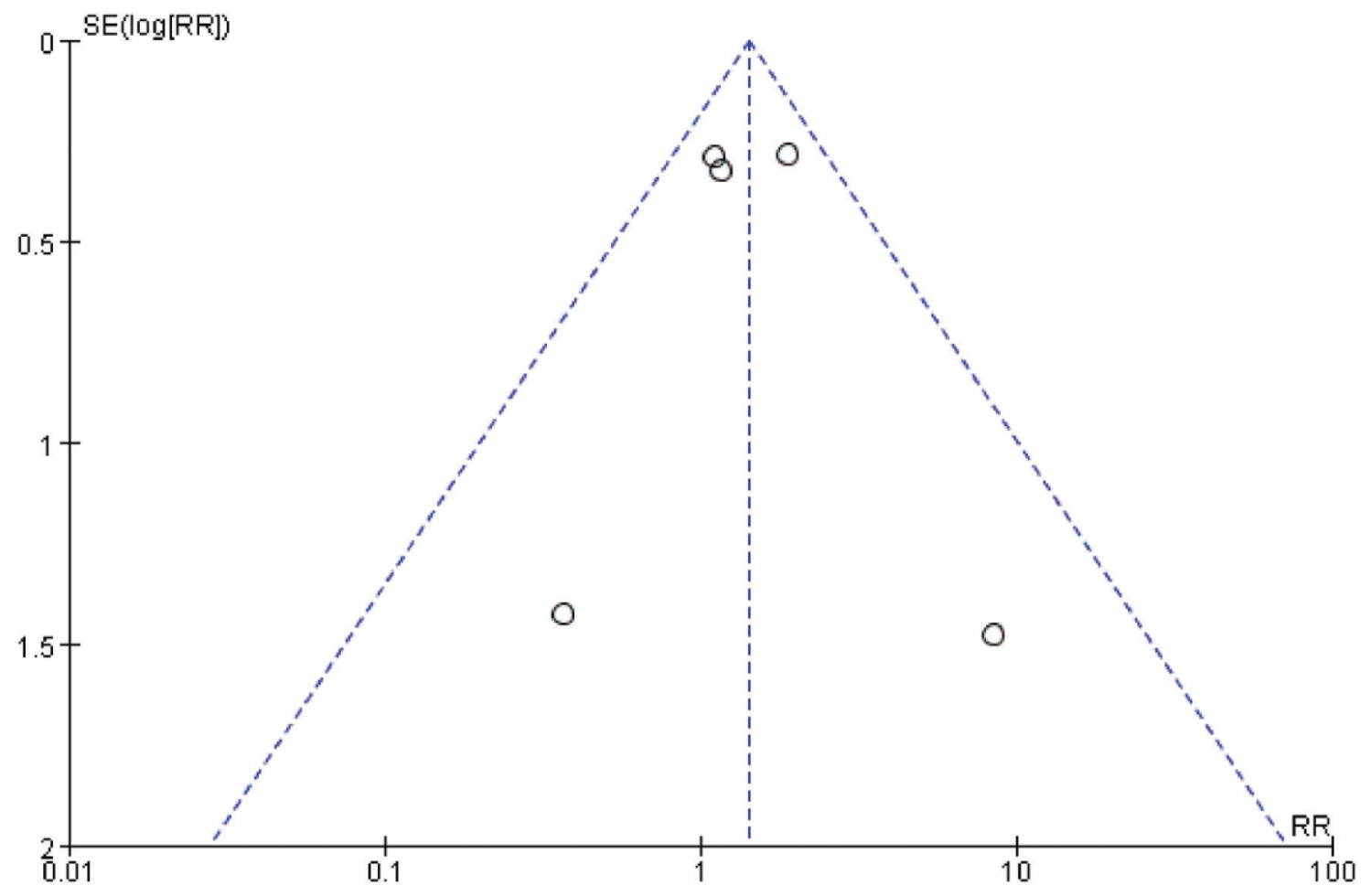

Fig. 2. Funnel plot showed no publication bias. 


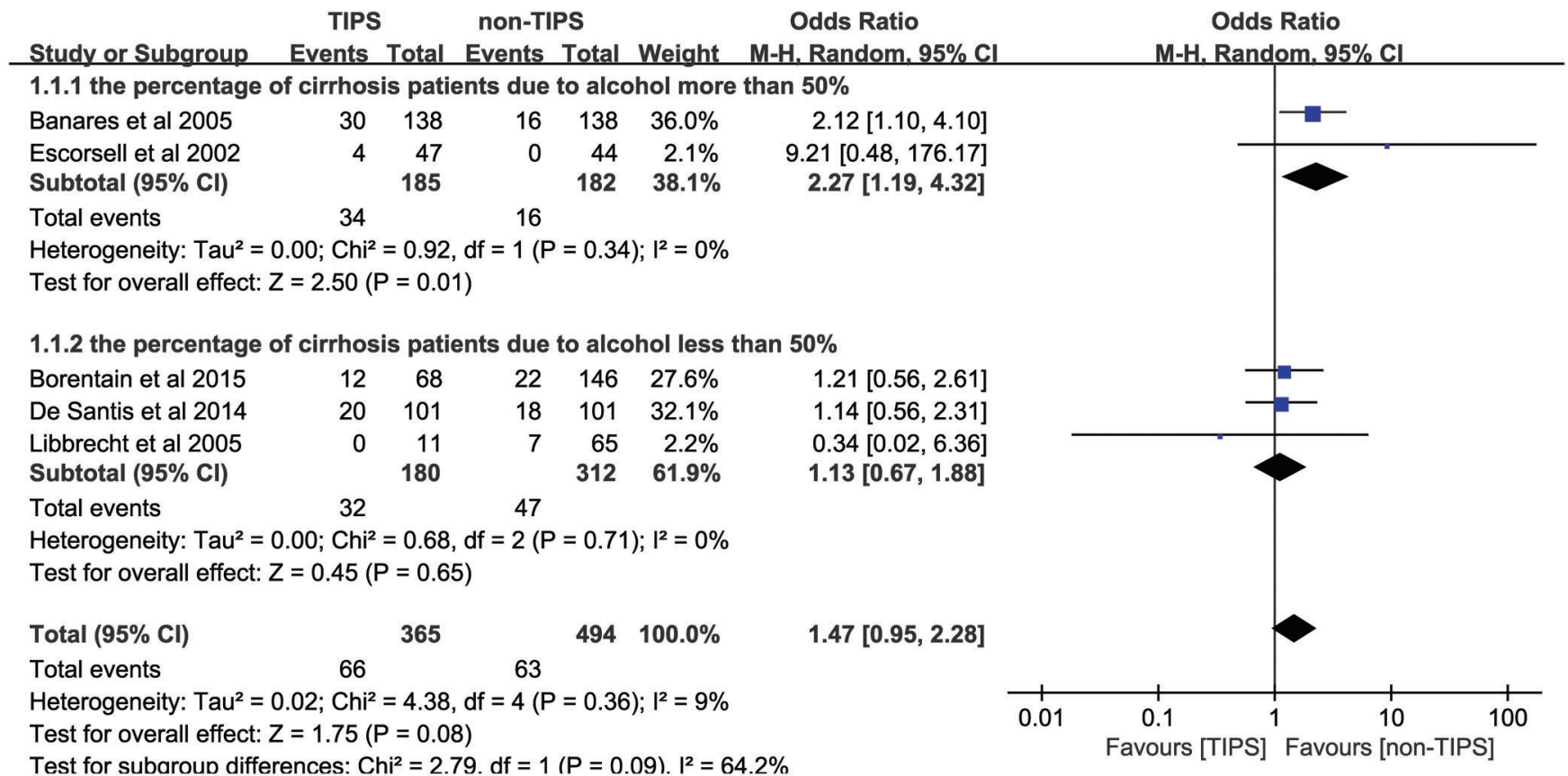

Fig. 3. Pooled estimates with random-effects model did not demonstrate a significant increase of incidence of HCC after TIPS, compared with other treatments. Abbreviations: HCC, hepatocellular carcinoma; TIPS, transjugular intrahepatic portosystemic shunt.

because changes in hepatic blood flow have been suggested to be associated with the development of nodular regenerative hyperplasia in patients with chronic Budd-Chiari syndrome. ${ }^{21}$ Borentain and his colleagues ${ }^{17}$ further demonstrated that the percentage of patients presenting with dysplastic nodules was higher in their TIPS group than the non-TIPS group (33.9\% vs. $20.1 \%, p=0.047)$. However, another study reported by Libbrecht et al. ${ }^{13}$ showed that the presence and number of dysplastic nodules was about 2 to 2.5 times lower in patients with a TIPS. To date, no special study has been conducted to explore the mechanisms through which TIPS placement could initiate the development of HCC. One published study suggested that TIPS was associated with the augmentation of hepatic iron deposits and the vascular and parenquimal changes. ${ }^{12}$ Another study found pseudointimal hyperplasia in the lumen of bare-stent TIPS, which may also play a role in the development of $\mathrm{HCC}^{22}$ However, this problem could be avoided in the era of covered-stent utilization in the TIPS procedure.

Although there is no significant heterogeneity between studies, and no publication bias, there are several limitations to our meta-analysis. First, there have been many trials evaluating the efficacy of portal-systemic shunt in the management of variceal bleeding; $;^{7,23-27}$ however, they mainly focused on the outcome of survival and did not pay attention to the association between portal-systemic shunt and development of HCC. So, only five studies were included in this meta-analysis. Second, the study designs varied from randomized controlled trials to observational cohort studies. Although most were of high quality, the inclusion criteria for patients varied, with some studies including only patients with transplanted liver. Third, the follow-up duration varied significantly, which might have influenced the incidence rate of HCC after treatment. We pooled the incidence rate of HCC at the last follow-up time from each included study, which would introduce some bias. So the random-effects model was used in our meta-analysis, in order to minimize the influence of heterogeneity between studies on the pooled estimates. Lastly, we only enrolled one randomized controlled trial, which makes future studies needed to fully elucidate the association between portal-systemic shunt and development of HCC.

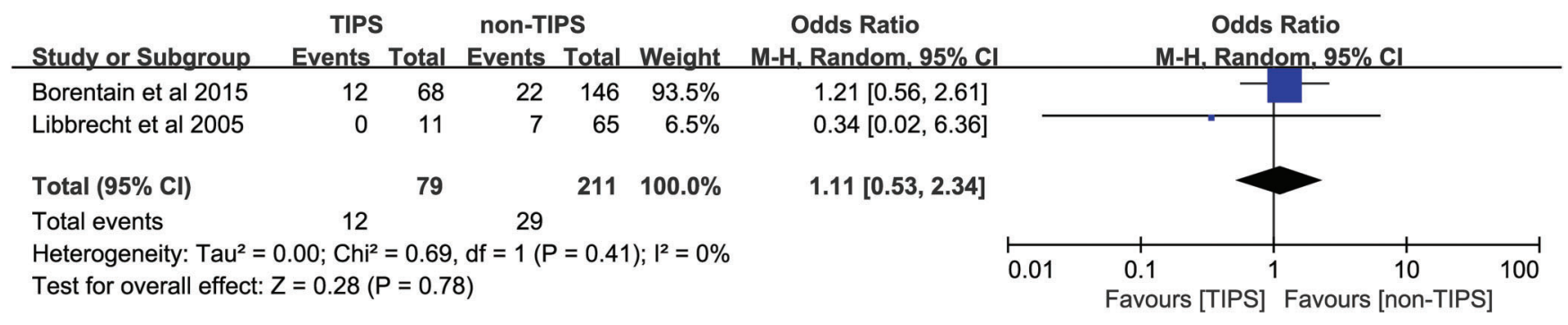

Fig. 4. Subgroup analysis for those patients with transplanted liver also did not detect a significant difference between TIPS group and non-TIPS group. Abbreviations: HCC, hepatocellular carcinoma; TIPS, transjugular intrahepatic portosystemic shunt. 
Chen B. et al: TIPS is not related to HCC

\section{Conclusions}

Creation of TIPS is not associated with increased risk of HCC development in patients with cirrhosis. This meta-analysis may further reassure physicians of this lack of association. Nevertheless, considering the natural history of cirrhosis and inherent residual risk of HCC development, which is not addressed by the use of TIPS, clinicians should remain vigilant to the HCC risk in these patients.

\section{Conflict of interest}

The authors have no conflict of interests related to this publication.

\section{Author contributions}

Searched literature and assessed methodological quality $(B C)$, selected studies for inclusion and extracted data (LP), analyzed and interpreted the data (BC, DBW, YHW, and $\mathrm{HBC}$ ), and wrote the manuscript (BC and LP), designed the study, provided administrative support, and final approval of manuscript (EQC), all authors approved the final manuscript.

\section{References}

[1] Richter GM, Noeldge G, Palmaz JC, Roessle M, Slegerstetter V, Franke M, et al. Transjugular intrahepatic portacaval stent shunt: preliminary clinical results. Radiology 1990;174:1027-1030. doi: 10.1148/radiology.174.3. 174-3-1027.

[2] Pomier-Layrargues G, Villeneuve JP, Deschênes M, Bui B, Perreault $P$, Fenyves $D$, et al. Transjugular intrahepatic portosystemic shunt (TIPS) versus endoscopic variceal ligation in the prevention of variceal rebleeding in patients with cirrhosis: a randomised trial. Gut 2001;48:390-396. doi: 10 . 1136/gut.48.3.390.

[3] Jalan R, Forrest EH, Stanley AJ, Redhead DN, Forbes J, Dillon JF, et al. A randomized trial comparing transjugular intrahepatic portosystemic stent-shunt with variceal band ligation in the prevention of rebleeding from esophageal varices. Hepatology 1997;26:1115-1122. doi: 10.1002/hep. 510260505.

[4] Gülberg V, Schepke M, Geigenberger G, Holl J, Brensing KA, Waggershauser T, et al. Transjugular intrahepatic portosystemic shunting is not superior to endoscopic variceal band ligation for prevention of variceal rebleeding in cirrhotic patients: a randomized, controlled trial. Scand J Gastroenterol 2002;37: 338-343. doi: 10.1080/003655202317284255.

[5] Axley P, Ahmed Z, Ravi S, Singal AK. Hepatitis C virus and hepatocellular carcinoma: A narrative review. J Clin Transl Hepatol 2018;6:79-84. doi: 10.14218/JCTH.2017.00067.

[6] Ma KW, Chok KSH, Fung JYY, Lo CM. Liver transplantation for hepatitis B virus-related hepatocellular carcinoma in Hong Kong. J Clin Transl Hepatol 2018;6:283-288. doi: 10.14218/JCTH.2017.00058.

[7] García-Pagán JC, Caca K, Bureau C, Laleman W, Appenrodt B, Luca A, et al. Early use of TIPS in patients with cirrhosis and variceal bleeding. N Engl J Med 2010;362:2370-2379. doi: 10.1056/NEJMoa0910102.

[8] Elwan N, Salem ML, Kobtan A, El-Kalla F, Mansour L, Yousef M, et al. High numbers of myeloid derived suppressor cells in peripheral blood and ascitic fluid of cirrhotic and HCC patients. Immunol Invest 2018;47:169-180. doi: 10.1080/08820139.2017.1407787.

[9] Abdelfattah AAM, Rizk F, Hawash N, Hanafy A, El-Kalla F, Abd-Elsalam S. Randomized trial of preoperative administration of oral pregabalin for postoperative analgesia in patients scheduled for radiofrequency ablation of foca lesions in the liver. Int J Hyperthermia 2018;34:1367-1371. doi: 10. 1080/02656736.2018.1424946.
[10] Hanafy AS, Soliman S, Abd-Elsalam S. Rescue therapy for chronic hepatitis C virus infection after repeated treatment failures: Impact on disease progression and risk of hepatocellular carcinoma. Hepatol Res 2019;49:377-384. doi: 10.1111/hepr.13303.

[11] Bjørneboe M, Andersen JR, Christensen U, Skinhøj P, Jensen OM. Does a portal-systemic shunt increase the risk of primary hepatic carcinoma in cirrhosis of the liver? Scand J Gastroenterol 1985;20:59-64. doi: 10. 3109/00365528509089633.

[12] Bañares R, Núñez O, Escudero M, Fernández C, Vaquero J, Beceiro I, et al. Patients with cirrhosis and bare-stent TIPS may have increased risk of hepatocellular carcinoma. Hepatology 2005;41:566-571. doi: 10.1002/hep. 20576.

[13] Libbrecht L, Maleux G, Verslype C, Nevens F, Roskams T. Influence of TIPS on development of hepatocellular carcinoma in cirrhosis. Hepatology 2005;42: 236. doi: 10.1002/hep.20745.

[14] De Santis A, Iegri C, Kondili L, Riggio O, Salvatori FM, Catalano C, et al. Hepatocellular carcinoma in cirrhotic patients with transjugular intrahepatic portosystemic shunt: a retrospective case-control study. Dig Liver Dis 2014; 46:726-730. doi: 10.1016/j.dld.2014.04.009.

[15] Moher D, Liberati A, Tetzlaff J, Altman DG. Preferred reporting items for systematic reviews and meta-analyses: the PRISMA statement. Ann Intern Med 2009;151:264-269. doi: 10.7326/0003-4819-151-4-20090818000135.

[16] Higgins JP, Thompson SG, Deeks JJ, Altman DG. Measuring inconsistency in meta-analyses. BMJ 2003;327:557-560. doi: 10.1136/bmj.327.7414.557.

[17] Borentain P, Garcia S, Gregoire E, Vidal V, Ananian P, Ressiot E, et al. Transjugular intrahepatic porto-systemic shunt is a risk factor for liver dysplasia but not hepatocellular carcinoma: a retrospective study of explanted livers. Dig Liver Dis 2015;47:57-61. doi: 10.1016/j.dld.2014.09.009.

[18] Elizalde JI, Castells A, Planas R, Rodríguez-Iglesias MP, Bruix J, Brú C, et al. Prevalence of hepatocellular carcinoma in cirrhotic patients with portosystemic shunt. Cohort analysis. Gastroenterol Hepatol 1996;19:189-193.

[19] Escorsell A, Bañares R, García-Pagán JC, Gilabert R, Moitinho E, Piqueras B, et al. TIPS versus drug therapy in preventing variceal rebleeding in advanced cirrhosis: a randomized controlled trial. Hepatology 2002;35:385-392. doi: 10.1053/jhep.2002.30418.

[20] Wei J, Li H, Li C. Investigating the risk factors of hepatocellular carcinoma and survival analysis for cirrhosis after transjugular intrahepatic portosystemic shunt in treating portal hypertension. J Cancer Res Ther 2018;14:826832. doi: 10.4103/jcrt.JCRT_930_17.

[21] Cazals-Hatem D, Vilgrain V, Genin P, Denninger MH, Durand F, Belghiti J, et al. Arterial and portal circulation and parenchymal changes in BuddChiari syndrome: a study in 17 explanted livers. Hepatology 2003;37:510519. doi: 10.1053/jhep.2003.50076.

[22] Sanyal A], Mirshahi F. Endothelial cells lining transjugular intrahepatic portasystemic shunts originate in hepatic sinusoids: implications for pseudointimal hyperplasia. Hepatology 1999;29:710-718. doi: 10.1002/hep. 510290323.

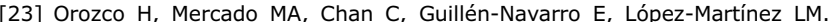
A comparative study of the elective treatment of variceal hemorrhage with beta-blockers, transendoscopic sclerotherapy, and surgery: a prospective, controlled, and randomized trial during 10 years. Ann Surg 2000;232:216219. doi: 10.1097/00000658-200008000-00011.

[24] Henderson JM, Kutner MH, Millikan WJ Jr, Galambos JT, Riepe SP, Brooks WS, et al. Endoscopic variceal sclerosis compared with distal splenorenal shunt to prevent recurrent variceal bleeding in cirrhosis. A prospective, randomized trial. Ann Intern Med 1990;112:262-269. doi: 10.7326/0003-4819-112-4262.

[25] Cello JP, Grendell JH, Crass RA, Weber TE, Trunkey DD. Endoscopic sclerotherapy versus portacaval shunt in patients with severe cirrhosis and acute variceal hemorrhage. Long-term follow-up. N Engl J Med 1987;316:11-15. doi: 10.1056/NEJM198701013160103.

[26] Cello JP, Grendell JH, Crass RA, Trunkey DD, Cobb EE, Heilbron DC. Endoscopic sclerotherapy versus portacaval shunt in patients with severe cirrhosis and variceal hemorrhage. N Engl J Med 1984;311:1589-1594. doi: 10. 1056/NEJM198412203112501.

[27] Lo GH, Liang HL, Chen WC, Chen MH, Lai KH, Hsu PI, et al. A prospective, randomized controlled trial of transjugular intrahepatic portosystemic shunt versus cyanoacrylate injection in the prevention of gastric variceal rebleeding. Endoscopy 2007;39:679-685. doi: 10.1055/s-2007-966591. 